\title{
TINJAUAN TEOLOGIS MENGENAI PEMAHAMAN UMAT TERHADAP INKULTURASI DAN DAMPAKNYA: STUDI KASUS GEREJA KATOLIK GANJURAN
}

\author{
Petrus Usmanij $^{* 1}$ dan Ganesha Muharram Akbar ${ }^{* 2}$ \\ ${ }^{1}$ Dosen La Trobe University, Australia \\ 2 Alumni Fakultas Teologia Universitas Kristen Satya Wacana, Salatiga \\ Email: ${ }^{1}$ p.usmanij@latrobe.edu.au, ${ }^{2}$ ganeshamuharram@gmail.com
}

\begin{abstract}
ABSTRAK-Tulisan ini membahas tentang pemahaman umat terhadap inkulturasi di Paroki Hati Kudus Tuhan Yesus Ganjuran yang bertujuan untuk memaparkan pemahaman, pandangan serta tanggapan umat terhadap inkulturasi di Gereja Katolik Paroki Hati Kudus Tuhan Yesus Ganjuran Jawa Tengah. Penelitian ini diharapkan agar dapat digunakan oleh Paroki Hati Kudus Tuhan Yesus Ganjuran untuk melihat bagaimana umat memandang dan menanggapi inkulturasi di Paroki Hati Kudus Tuhan Yesus Ganjuran. Data diperoleh melalui survei langsung ke lokasi penelitian dan menggunakan teknik wawancara dengan umat di Paroki Hati Kudus Tuhan Yesus di Ganjuran. Hasil Penelitian menunjukkan bahwa umat telah memahami inkulturasi sebagai penyesuaian dan pengakaran Injil ke dalam suatu budaya setempat serta menanggapi secara positif inkulturasi di Paroki Hati Kudus Tuhan Yesus Ganjuran yang telah umat menghayati pesan Injil serta berdampak bagi kehidupan peribadahan umat, seperti misalnya menimbulkan semangat untuk terus berdoa, berdevosi dan beribadah.
\end{abstract}

Kata kunci: Inkulturasi, Kebudayaan, Paroki Hati Kudus Tuhan Yesus Ganjuran

ABSTRAK-This paper discusses the people's understanding of inculturation in the Paroki Hati Kudus Tuhan Yesus Ganjuran which aims to explain the understanding, views and responses of the people to inculturation in the Catholic Church of Paroki Hati Kudus Tuhan Yesus Ganjuran Central Java. This research is expected to be used by the Paroki Hati Kudus Tuhan Yesus Ganjuran to see how people see and respond to inculturation in the Paroki Hati Kudus Tuhan Yesus Ganjuran. Data obtained through direct surveys to the research location and using interview techniques with people in the Paroki Hati Kudus Tuhan Yesus Ganjuran. The results of the study show that people have understood inculturation as the adaptation and stirring of the gospel into a local culture and responded positively to inculturation in the Paroki Hati Kudus Tuhan Yesus Ganjuran that people have lived the message of the Gospel and impacted the lives of worship of the people, such as creating enthusiasm to continue praying, devote and worship.

Key word: Inculturation, Culture, Paroki Hati Kudus Tuhan Yesus Ganjuran

\section{PENDAHULUAN}

Pembicaraan tentang kaitan antara iman dan kebudayaan selalu dibicarakan dalam kehidupan Gereja sebagai tubuh Kristus yang hadir di dunia selalu berjumpa dengan kebudayaan. Di tengah kenyataan tersebut, Gereja terdorong untuk menjawab tantangan tentang bagaimana iman dan kebudayaan dapat bertemu dan selaras. Salah satu upaya yang dilakukan Gereja untuk menyelaraskan iman dan kebudayaan adalah melalui Inkulturasi. 
Inkulturasi adalah istilah yang sekarang ini dibicarakan sebagai upaya yang dilakukan Gereja untuk menyelaraskan antara iman dan kebudayaan. Istilah ini digunakan oleh Gereja Katolik untuk menggambarkan upaya Gereja Katolik dalam menghayati iman dan mencari keselarasannya dengan kebudayaan. Franz Magnis Suseno bahkan menyatakan bahwa inkulturasi adalah ciri khas Katolik. ${ }^{1}$ Inkulturasi dipopulerkan sebagian besar oleh anggota Serikat Yesus. ${ }^{2}$ Menurut A.B Sinaga, inkulturasi adalah sejenis penyesuaian dan adaptasi kepada masyarakat, kelompok umat, kebiasaan, bahasa, dan perilaku yang biasa terdapat pada suatu tempat ${ }^{3}$. Tujuan dari inkulturasi adalah mengakarkan iman-iman Kristen ke dalam budaya setempat. Inkulturasi didasarkan pada inti iman Kristen itu sendiri yaitu inkarnasi Sabda Allah yang hadir ke dalam dunia dan menyapa manusia. Ketika Sabda Allah menyapa manusia, Ia berinkulturasi dengan budaya manusia, menggunakan bahasa manusia dan bukan bahasa langit atau bahasa surga, serta adat dan istiadat, dalam mengekspresikan kebenaran dan cinta kasih Allah. ${ }^{4}$ Oleh karena itu dapat disimpulkan bahwa proses inkulturasi didasarkan pada perjumpaan antara Kristus dan manusia sendiri.

Iman dan kebudayaan tidak dapat dipisahkan dan saling berhubungan untuk mencapai kepenuhan proses dan tujuan

${ }^{1}$ Franz Magnis Suseno, Katolik itu Apa?: Sosok, Ajaran, dan Kesaksiannya (Yogyakarta: Penerbit PT Kanisius, 2017), 20.

2 Aylward Shorter, Toward a Theology of Inculturation, ( New York: Orbis Books, 1988), 10.

3 A.B Sinaga, Gereja dan Inkulturasi, (Yogyakarta: Penerbit PT Kanisius, 1984), hal. 8

4 Yunita Setyoningrum, "TINJAUAN INKULTURASI AGAMA KATOLIK DENGAN BUDAYA JAWA PADA BANGUNAN GEREJA KATOLIK DI MASA KOLONIAL BELANDA (STUDI KASUS : GEREJA HATI KUDUS YESUS, PUGERAN, YOGYAKARTA)", Jurnal Ambiance 1, no. 1 (2009), 5-6. inkulturasi. Keduanya menyangkut dimensi paling dalam dan fundamental dalam hidup manusia. Manusia memahami kebudayaan sebagai lingkup di mana mereka harus hidup dan juga ukuran dalam hidup dan tingkah laku manusia. ${ }^{5} \mathrm{Di}$ dalam kebudayaan, manusia belajar untuk memaknai hidup dan menjadi manusia seutuhnya. Hal ini juga dijelaskan dalam Konsili Vatikan II Gaudium et Spes yang menyatakan "kebudayaan dimaksudkan segala sarana dan upaya manusia untuk menyempurnakan dan mengembangkan pelbagai bakat-pembawaan-jiwa raganya". 6 Namun dalam prosesnya menjadi manusia sejati, manusia juga menghayati relasinya dengan yang ilahi. ${ }^{7}$ Penghayatan manusia terkait relasinya dengan yang ilahi itulah yang biasa disebut dengan iman. Dari penjelasan tersebut dapat kita simpulkan bahwa hubungan antara iman dan kebudayaan terlihat sebagai proses menjadi seorang manusia yang sejati. Iman tidak dapat menemukan implikasinya dalam kebudayaan. Pernyataan ini ditegaskan juga oleh Paus Yohanes Paulus II yang menyatakan bahwa iman yang belum menjadi kebudayaan merupakan iman yang belum dihidupi sepenuhnya. ${ }^{8}$

Gereja Katolik di Indonesia dalam dinamika hidup bergereja berusaha untuk berinkulturisasi dengan budaya Indonesia. Hal ini ditunjukkan dengan digunakannya bahasa-bahasa daerah dan musik-musik

5 Budiono Herusato, Simbolisme Jawa, (Yogyakarta: Penerbit Ombak, 2008), cetakan ke II, 10-11.

6 Konsili Vatikan II, Dokumen Konsili Vatikan II: Gaudium et Spes, terj. R. Hardawiryana, (Jakarta: Penerbit Obor, 2012), 594.

${ }^{7}$ Yohanes Agung Hari Prastowo, Peranan Inkulturasi Budaya Jawa Terhadap Penghayatan Ekaristi di Paroki Hati Kudus Tuhan Yesus GanjuranI. (Skripsi., Universitas Sanata Dharma, 2012), 1.

${ }^{8}$ Anicetus B. Sinaga, Gereja dan Inkulturasi, (Yogyakarta: Penerbit PT Kanisius, Yogyakarta, 1984), 3. 
tradisional dalam liturgi misa. Semua itu merupakan bentuk Jawaban dari tantangan umat Katolik di Indonesia terhadap hubungan iman dan kebudayaan. Sehingga Gereja Katolik di Indonesia menjadi Gereja Katolik Indonesia. ${ }^{9}$ Proses inkulturisasi juga berlangsung di gereja-gereja yang tersebar di wilayah Indonesia. Salah satu contoh dari inkulturasi iman dan budaya adalah Paroki Hati Kudus Tuhan Yesus Ganjuran yang menjadi studi kasus di dalam penelitian ini.

Paroki Hati Kudus Tuhan Yesus Ganjuran adalah Gereja Katolik yang berada di naungan wilayah keuskupan agung Semarang. Gereja ini terletak di dusun Ganjuran, desa Sumbermulyo, kecamatan Bambanglipuro, daerah Bantul. Letak gereja ini berada sekitar 20 kilometer dari Yogyakarta.

\section{RUMUSAN MASALAH}

Adapun rumusan masalah dari penelitian ini adalah sebagai berikut: Pertama, Bagaimana pemahaman umat di Paroki Hati Kudus Tuhan Yesus Ganjuran tentang inkulturasi di gereja ini? Kedua, Apa dampak inkulturisasi di Paroki Hati Kudus Tuhan Yesus Ganjuran menurut umat?
9 Pernyataan ini sama seperti judul pada sampul buku Indonesianisasi: Dari Gereja Katolik di Indonesia Menjadi Gereja Katolik Indonesia karangan Dr. Huub J.W.M Boelaars, OFM Cap, (Yogyakarta: Kanisisus, 2005).
Tujuan dari penulisan ini adalah: Pertama, mengetahui pandangan umat tentang Inkulturisasi di Paroki Hati Kudus Yesus Ganjuran. Kedua, mengetahui dampak inkulturasi di Paroki Hati Kudus Tuhan Yesus Ganjuran menurut umat. Sedangkan manfaat dari penulisan ini adalah: pertama, secara teoritik: untuk menambah dan melengkapi pengetahuan di Fakultas Teologi Universitas Kristen Satya Wacana tentang inkulturasi. Kedua, kepada pihak Paroki Hati Kudus Tuhan Yesus Ganjuran: memberikan gambaran tentang pemahaman umat tentang inkulturisasi serta mengetahui dampak inkulturisasi menurut umat.

\section{Inkulturasi}

Istilah inkulturasi sebenarnya adalah istilah yang baru dalam Gereja Katolik yang dipakai tahun 1973 oleh G.L Barney, yang mengatakan bahwa di tanah misi nilai-nilai Injil yang adibudaya dan mau diwartakan kepada orang-orang setempat, haruslah diinkulturasikan ke dalam budaya orang setempat sehingga menghasilkan budaya baru yang bersifat Kristen. ${ }^{10}$ Walaupun begitu Inkulturasi adalah proses yang telah lama dilakukan oleh Gereja Katolik terutama di kalangan Serikat Jesuit.

Secara etimologi inkulturasi terdiri dari kata in dan cultura. In mengandung makna masuk ke dalam. Sedangkan kata cultura atau dalam bahasa latinnya adalah kolere memiliki arti yang berarti mengolah tanah atau lebih lanjut mengandung arti yaitu kebudayaan. ${ }^{11}$ Dari etimologi tersebut

10 Boli Ujan SVD, "Penyesuaian dan Inkulturasi Liturgi”, last modified 6 Agustus 2010,

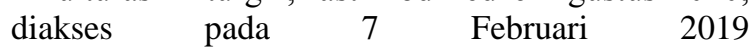
http://www.katolisitas.org/penyesuaian-daninkulturasi-liturgi/.

${ }^{11}$ Lucia Esti Elihami, Sejarah Berdirinya Paroki Hati Kudus Yesus Ganjuran: Inkulturasi sebagai Landasan Tumbuh dan Berkembangnya Paroki Hati Kudus Yesus Ganjuran Yogyakarta (Skripsi, Universitas Sanata Dharma, 1995), 19. 
maka istilah inkulturasi berarti adalah masuk ke dalam kebudayaan.

Seperti telah ditulis oleh A.B Sinaga pada Pendahuluan, inkulturasi memiliki arti yang sama dengan penyesuaian, dan adaptasi kepada masyarakat, kelompok umat, kebiasaan, bahasa, dan perilaku yang biasa terdapat pada suatu tempat. Definisi yang diberikan oleh A.B Sinaga lebih mengarah ke dalam definisi dalam arti secara sosiologis. Menurut A.B Sinaga, penyesuaian diperlukan agar Injil yang diwartakan dapat dimengerti dan dipahami. Definisi dari A.B Sinaga juga memiliki kesamaan definisi inkulturasi menurut $\mathrm{A}$. Soenarja yang menyatakan bahwa Inkulturasi adalah "usaha masuk ke dalam suatu kultur", meresapi suatu kebudayaan dan menjadi senyawa dengan suatu kultur. ${ }^{12}$

Definisi yang hampir sama dengan A.B Sinaga namun berbeda secara perspektif dikemukakan oleh Fr Pedro Arrup SJ yang mendefinisikan inkulturasi sebagai:

"The Incarnation of Christian life and of the Christian message in particular context, in such a way that this experience not only finds expression through elements proper to the culture in question but becomes a principle that animates, directs and unifies the culture, transforming it and remaking it so as to bring about a 'new creation'.

Dari definisi yang diberikan oleh Fr Pedro Arrup SJ dapat disimpulkan bahwa inkulturasi adalah penjelmaan pewartaan Kristen dalam budaya tertentu secara dinamis dan kreatif. Berbeda dengan kalangan Injili yang berpegang pada

12 A. Soenarja, Inkulturisasi (Indonesianisasi): Kepemimpinan dan Kekeluargaan dalam Biara di Indonesia di masa sekarang, (Yogyakarta: Penerbit Kanisius, 1974), 5.

${ }^{13}$ Aylward Shorter, Toward a Theology of Inculturation, (New York: Orbis Books, 1988), 14. kontekstualisasi ${ }^{14}$. Proses dinamis dan kreatif antara Injil dan kebudayaan tersebut membawanya kepada tujuan dan puncak dari proses inkulturasi yaitu 'ciptaan baru'. Definisi pengertian inkulturasi yang diberikan oleh Fr Pedro Arrup SJ memiliki kemiripan dengan definisi inkulturasi yang dipaparkan oleh Paus Yohanes Paulus II. Menurut Paus Yohanes Paulus II, inkulturasi adalah inkarnasi nilai-nilai Injil dalam pelbagai budaya yang otonom dan sekaligus memasukkan budaya-budaya tersebut ke dalam kehidupan Gereja. ${ }^{15}$ Jadi menurut Paus Yohanes Paulus II, inkulturasi adalah pemasukan budayabudaya ke dalam kehidupan Gereja.

Dari etimologi dan definisi beberapa tokoh tentang inkulturasi yang telah dipaparkan diatas dapat disimpulkan bahwa inkulturasi adalah sebuah proses penyesuaian, penyelarasan atau penjelmaan Injil ke dalam suatu budaya tertentu.

\section{Inkulturasi dari Peristiwa Inkarnasi}

Inkarnasi merupakan pusat dari iman Kristen yang adalah penjelmaan Sabda Allah ke dalam wujud manusia. Inkarnasi sabda Allah yang datang ke dalam dunia dan mengambil wujud manusia. Dalam melandaskan dasar teologis tentang Inkulturasi, Gereja Katolik merefleksikan peristiwa inkarnasi sabda Allah ke dalam dunia sebagai titik awal dari teologi Inkulturasi. Penggunaan analogi peristiwa inkarnasi sebagai titik awal dari Inkulturasi digunakan dalam dokumen Konsili Vatikan II Gaudium et Spes pasal 58 tentang hubungan antara warta gembira tentang Kristus dan kebudayaan manusia. ${ }^{16}$

\footnotetext{
${ }^{14}$ Roger L. Dixon, Injil dan kontekstualisasi: Sebuah cara kontekstualisasi masa kini yang kurang memadai, Jurnal Pelita Zaman, 11(2), 1996

15 Boli Ujan SVD, "Penyesuaian dan Inkulturasi Liturgi."

${ }^{16}$ [ Ada bermacam-macam hubungan antara warta keselamatan dan kebudayaan. Sebab, Allah, yang mewahyukan diri-Nya sepenuhnya dalam
} 
Ketika Ia menjelma menjadi manusia, Ia menghayati hidup manusia yang otentik, Ia berbicara dalam bahasa manusia, Ia hidup dalam budaya manusia, bahkan Ia menggunakan budaya sebagai cara Ia mewartakan keselamatan Allah. ${ }^{17}$ Pemahaman inkarnasi sebagai dasar inkulturasi sebagaimana dipahami tadi menunjukkan dekatnya Allah dengan manusia.

Dalam kaitannya dengan budaya, inkarnasi menunjukkan bahwa Allah menjelma ke dalam budaya dan memakai budaya untuk menyelamatkan dan mengubah manusia yang jatuh ke dalam dosa. Implikasinya bagi gereja adalah sama seperti Allah yang menjelma menjadi manusia, begitu juga Gereja harus "berinkarnasi" dengan budaya di mana ia dipanggil dan diutus dan menjadi senyawa dengan kultur-kultur lain dengan begitu pewartaan keselamatan yang diwartakan gereja dapat menjadi bermakna dan hidup. ${ }^{18}$

Analogi inkarnasi yang digunakan sebagai dasar teologi inkulturasi memiliki indikasi-indikasi. Menurut Shorter, analogi Inkarnasi sebagai dasar dari teologi inkulturasi, memiliki 3 indikasi. Pertama,

Putra-Nya yang menjelma, telah bersabda menurut kebudayaan yang khas bagi pelbagai zaman...] R. Hardawiryana, diterjemahkan., Dokumen Konsili Vatikan II, (Jakarta: Penerbit OBOR, 2013, cetakan ke 12, 600.

17 Yunita Setyoningrum,"TINJAUAN INKULTURASI AGAMA KATOLIK DENGAN BUDAYA JAWA PADA BANGUNAN GEREJA KATOLIK DI MASA KOLONIAL BELANDA (STUDI KASUS : GEREJA HATI KUDUS YESUS, PUGERAN, YOGYAKARTA): ANALYSIS OF CHRISTIAN INCULTURATION TO JAVANESE CULTURE ON CATHOLIC CHURCH BUILT ON THE DUTCH COLONIAL PERIOD (STUDI KASUS : THE CHURCH OF SACRED HEART, PUGERAN, YOGYAKARTA)", Jurnal Ambiance 1, no. 1 (2009), 5

18 A. Soenarja, Inkulturisasi (Indonesianisasi): Kepemimpinan dan Kekeluargaan dalam Biara di Indonesia di masa sekarang, (Yogyakarta: Penerbit Kanisius, 1974), 6. mengindikasikan bahwa analogi ini memenuhi tujuan dari Kristologi dari atas. ${ }^{19}$ Maksudnya adalah tujuan dari inkulturasi disamakan dengan inkarnasi sabda Allah ke dalam tubuh manusia. Sabda Allah berinkarnasi dan mengambil rupa manusia dan hidup di tengah-tengah budaya. Kedua, analogi ini mengindikasikan bahwa Kristus menggunakan budaya untuk mewartakan Injil kerajaan Allah dan berbagi kehidupannya dengan manusia. Dengan kata lain, pelayanan Yesus yang membumi atau berkesan bagi pendengarnya adalah karena di dalam pelayananNya Yesus mengadopsi konsep budaya, simbol, dan tingkah laku para pendengarnya. Ketiga, Pendidikan budaya yang membumi dari Yesus, adopsiNya dari budaya manusia yang spesifik, menempatkan Yesus ke dalam seluruh proses komunikasi antara budaya. Dengan mengadopsi identitas budaya tertentu, Yesus menerima cara di mana budaya terpengaruh, dan dipengaruhi oleh budaya lain. ${ }^{20}$ Maksud Shorter adalah Kristus juga terlibat ke dalam komunikasi yang terjadi di dalam budaya. Implikasinya adalah seperti yang telah dijelaskan Shorter bahwa Kristus menyesuaikan diri dengan arus budaya dan nilai-nilai kehidupan di tempat Ia menjalankan misiNya.

Walaupun istilah inkarnasi memiliki indikasi-indikasi yang baik dan menarik sebagai dasar teologi inkulturasi namun ada beberapa kekurangan dari istilah ini sebagai dasar dari teologi inkulturasi. Pertama, jika teologi inkulturasi bertitik pangkal hanya dari inkarnasi maka keseluruhan misteri Kristus dan kaitannya dengan kebudayaan tidak diperhatikan. Dalam berinkulturasi,

19 Metode Kristologi yang mendekati dan menafsirkan Yesus Kristus sebagai sosok yang ilahi. Yusak B. Setyawan, Kristologi: Perkenalan, Pendalaman, dan Pergumulan (Bahan Kuliah dalam Progres), (Salatiga: Fakultas Teologi, Universitas Kristen Satya Wacana, 2015), 9.

${ }^{20}$ Aylward Shorter, Toward a Theology of Inculturation, (New York: Orbis Books, 1988), 80. 
tidak boleh lupa untuk melibatkan keseluruhan misteri Kristus yang meliputi inkarnasi, pengorbanan Kristus, dan kebangkitanNya dalam kaitannya dengan kebudayaan. Hal ini juga disampaikan oleh Frans Xavier Scheuerer yang menyatakan "untuk mendasarkan inkulturasi hanya berpangkal pada misteri Inkarnasi tanpa menghubungkan kepada keseluruhan misteri Kristus sangat tidak memadai". ${ }^{21}$ Kedua, menurut Shorter, Penggunaan Inkarnasi sebagai dasar dan model dari inkulturasi akan mendorong pribadi seseorang untuk mengalah pada godaan kebudayaan. $^{22}$

\section{Misteri Paskah dan Inkulturasi (A. Shorter)}

Teologi inkulturasi yang selama ini hanya berlandaskan pada misteri Inkarnasi belumlah memadai. Pendapat yang dianggap sebagai pionir dalam inkulturisasi adalah dari seorang misionaris Inggris, Aylward Shorter. Menurut Shorter, gambaran inkulturasi yang lebih jelas dan akurat akan nampak apabila Misteri Paskah digunakan sebagai analogi, daripada hanya dilandaskan pada peristiwa inkarnasi.

Secara tujuannya, menurut Shorter, misteri paskah dan inkarnasi tidak terpisahkan. Inkarnasi mengambil bagian supaya kemanusiaan dapat diselamatkan dan dibenarkan (1 Tim 2:4). Pekerjaan penyelamatan itu diselesaikan secara prinsip melalui misteri paskah, pengurbanan penebusan Kristus di kayu salib dan kebangkitanNya-kenaikanNya ke dalam kemuliaan sebagai Tuhan. Yesus mati, seumpama semua manusia dipanggil untuk "mati", tetapi kebangkitannya

${ }^{21}$ Jose Pedro Angelico, Inculturation As Self Identification: An African in Research of Authentic Christian Identity. A Theological Enquiry Among The Ewe of Ghana (Diss., UNIVERSIDADE CATÓLICA PORTUGUESA, 2016), 18.

${ }^{22}$ Aylward Shorter, Toward a Theology of Inculturation, 82. memberikannya bentuk baru yang sepenuhnya dari eksistensi manusia.

Terlepas dari hubungan kausal antara Misteri Paskah dan inkulturasi, menurut Shorter, ada pertanyaan lebih lanjut dari penggunaan Misteri Paskah sebagai analogi untuk Inkulturasi. Kristus mati dan bangkit lagi. Apakah itu berarti bahwa setiap budaya harus mati dan bangkit kembali ketika dihadapkan dengan kebangkitan Kristus? ${ }^{23}$ Proklamasi Injil tentang kebangkitan Kristus adalah sebuah tantangan bagi tradisi manusia. Dengan kebangkitan Kristus, budaya diinjili dan dibawa untuk bertobat atau berubah. Lalu apakah dengan begitu tetap saja Injil mengatasi budaya? Atau apakah yang dimaksud Shorter bahwa dengan kebangkitan budaya dibawa untuk bertobat atau berubah? Bertobat dan berubah dari apa? Shorter menyatakan bahwa budaya tidak selamanya setia kepada nilai-nilai yang baik dan paling benar. Artinya adalah di dalam budaya sendiri, terdapat nilai-nilai yang tidak sesuai dengan nilai kemanusiaan. Budaya bisa saja destruktif dan berdosa. Kebangkitan Kristus mengajak budaya untuk 'mati'. Mereka harus 'mati' kepada nilai-nilai dalam kebudayaan mereka yang tidak pantas bagi kemanusiaan, dan semua yang merupakan konsekuensi dari kesalahan dan dosa sosial. ${ }^{24}$

Dari maksud kebangkitan Kristus menurut Shorter, menjadi jelas bahwa, budaya dipanggil oleh Kristus untuk 'mati' untuk segala sesuatu yang bertentangan dengan kemanusiaan. Kebangkitan Kristus tidak bermaksud untuk mengubah kebudayaan, tetapi dengan kebangkitan Kristus, budaya dibersihkan dan dibawa kepada ujian salib, tempat di mana nilai baru pada setiap aksi, setiap kejadian, setiap

${ }^{23}$ Aylward Shorter, Toward a Theology of Inculturation, 83.

${ }^{24}$ Aylward Shorter, Toward a Theology of Inculturation, 84. 
kata atau pemikiran diangkat. ${ }^{25}$ Pernyataan Shorter ini hendak juga memberikan suatu tujuan kepada Gereja dalam kaitannya dengan proses inkulturasi. Gereja melakukan inkulturasi bukan berarti gereja hanya menyesuaikan diri dengan budaya setempat. Di tempat dan budaya di mana Gereja hidup sebagai komunitas kaum beriman, Gereja harus melihat dan peka kepada nilai-nilai dalam budaya yang tidak sesuai dengan nilai-nilai kemanusiaan atau nilai dari Kristus sendiri dan membawanya kepada 'ciptaan' baru.

Shorter menyatakan kembali bahwa penggunaan analogi Misteri Paskah sebagai dasar Inkulturasi tidak boleh sampai kepada pandangan yang statis tentang Inkulturasi. "Kristus bangkit dan tidak dapat lagi mati". Menurut Shorter adalah benar bahwa dalam misteri Paskah konflik antar manusia diselesaikan dan kemuliaanNya kekal dan tidak berubah. Tetapi hal itu tidak untuk masa depan evangelisasi atau dengan kata lain proses inkulturasi. Inkulturasi adalah proses dinamika injil dan budaya yang terus berlangsung dan berlanjut. ${ }^{26}$ Proses dinamika tersebut tidak bisa secara definitive selesai sampai akhir dari sejarah. Hal itu karena budaya bukanlah suatu fenomena yang statis. Budaya adalah proses pengembangan yang berkelanjutan dan berubah, saat ia bertindak dan bereaksi dalam komunikasi yang terjadi di antara budaya. Dengan kata lain, Shorter mau menunjukkan bahwa budaya bukanlah hal yang tetap tapi akan terus berubah sesuai dengan waktu dan keadaan.

Jadi dari dasar teologis dari inkulturasi baik itu didasari dari peristiwa inkarnasi atau misteri Paskah tidak dapat dipisahkan satu sama lain. Kedua analogi itu mencakup dimensi kehadiran Kristus di dunia dan tujuannya hadir di tengah-tengah

${ }^{25}$ Aylward Shorter, Toward a Theology of Inculturation, 84.

${ }^{26}$ Aylward Shorter, Toward a Theology of Inculturation, 85. budaya. Keduanya juga saling melengkapi dan tidak bertentangan satu sama lain. Kedua analogi itu juga memberikan dampak bagi dasar dari teologi dan praksis inkulturisasi yang dipahami dan digiatkan Gereja.

\section{Metode Inkulturasi}

Menurut A.B Sinaga, inkulturasi Injil dalam budaya setempat mempunyai tahap-tahap sebagai berikut. Tahap pertama yaitu, melakukan penyesuaian dan adaptasi kepada masyarakat, kelompok umat, kelompok umat, kebiasaan, bahasa dan perilaku yang biasa terdapat pada suatu tempat. Ini mengacu pada tahap pertama ketika misionaris pertama kali datang ke suatu budaya. Pada tahap ini, Gereja menyesuaikan diri dan melakukan adaptasi, serta belajar dengan budaya di mana Ia hadir.

Tahap kedua, adalah yang disebut oleh A.B Sinaga sebagai 'masa inkubasi'. Pada tahap ini Injil yang ditaburkan dan diwartakan mulai jatuh dalam budaya dan kebiasaan setempat. Pada tahap ini Injil mulai meragi, meresapi, dan bersenyawa dengan kebudayaan setempat. Pada tahap ini Injil juga mulai untuk meneyentuh hati dan jiwa pendengar, kemudian dihayati dan dijiwai. Inilah yang disebut sebagai "incarnatio in actu secondo". ${ }^{27}$ Pada tahap ini juga hal-hal yang belum bisa diperdamaikan dibiarkan dan 'diragikan' lebih dahulu.

Tahap ketiga, tahap ketiga ini akan tercapai apabila kesadaran akan Injil seseorang mulai secara sengaja menata pola tindakan dan berprikirnya. ${ }^{28}$ Pada tahap ini seseorang yang sadar dan dipengaruhi oleh Roh Kudus, mulai untuk meninggalkan kebiasaan yang lama yang bertentangan dengan Injil. Hal-hal yang kurang berpadanan dengan pesan Injil juga

\footnotetext{
${ }^{27}$ A.B Sinaga, Gereja dan Inkulturasi, 8.

${ }^{28}$ A.B Sinaga, Gereja dan Inkulturasi, 8.
} 
disingkirkan. Pada tahap ini pengkhotbah dan pewarta bersama-sama dengan umat mencari ungkapan-ungkapan yang lebih cocok dan lebih harmonis dan selaras dengan khazanah kebudayaan setempat tetapi serentak lebih berwarna Kristen dalam mutu dan bobot. ${ }^{29}$

Tahap keempat, ialah secara sengaja dan mendalam menganalisa unsur-unsur yang ada, baik yang berasal dari budaya lama dan diperbaharui maupun dari khazanah permata-permata Injil, yang lebih bernas, untuk mengembangkan suatu teologi dan basis yang mantap untuk membangun keKristenan yang mantap dan dewasa. $^{30}$

Dari tahap-tahap inkulturasi yang dipaparkan oleh A.B Sinaga dapat diambil kesimpulan bahwa persoalan Inkulturasi bukan hanya suatu permasalahahan yang hanya dikerjakan oleh para teolog. Inkulturasi adalah proses di mana antara teolog, pemimpin umat, dan umat itu sendiri bekerja supaya pesan Injil yang mengakar dalam budaya itu benar-benar dihayati dan memberikan makna sendiri bagi Gereja.

\section{Sikap Kekristenan terhadap Kebudayaan}

Sepanjang kehidupan Gereja, hubungan antara Gereja dengan kebudayaan mendapat perhatian sejak awal Gereja bahkan terus dibahas sampai sekarang. Menurut Richard Niebuhr setidaknya ada lima sikap keKristenan dalam hubungannya dengan kebudayaan yaitu Kristus lawan kebudayaan, Kristus dari kebudayaan, Kristus di atas kebudayaan, Kristus dan kebudayaan dalam paradoks dan Kristus pengubah kebudayaan. Titik tolak dari kelima sikap itu dipusatkan kepada Kristus yang adalah Anak Allah dan pusat dari iman Kristen. Dari kelima sikap tersebut

\footnotetext{
${ }^{29}$ A.B Sinaga, Gereja dan Inkulturasi, 9.

${ }^{30}$ A.B Sinaga, Gereja dan Inkulturasi, 9.
}

ada tiga yang merujuk ke inkulturasi yaitu Kristus di atas kebudayaan, Kristus dan kebudayaan dalam paradoks, dan Kristus pengubah kebudayaan.

Kristus di atas Kebudayaan merujuk kepada sikap tidak mengambil posisi anti terhadap budaya secara radikal tetapi juga akomodator Kristus ke dalam kebudayaan. ${ }^{31}$ Permasalahan utama bukan terletak antara Kristus dengan kebudayaan, tetapi permasalahan yang penting adalah antara Tuhan dan manusia. Pandangan dari sikap ini tidak memandang budaya sebagai sesuatu yang buruk sebab Kristus adalah yang adalah Anak Allah pencipta langit dan bumi oleh karena itu budaya tetap dianggap sebagai ciptaan yang baik dan benar yang dihadirkan Allah. ${ }^{32}$

Kristus dan Kebudayaan dalam Paradoks adalah dalam hal Gereja berkeinginan untuk mempertahankan kesetiaan mereka kepada Kristus dan di sisi lain ingin mempertahankan tanggung Jawab terhadap budaya secara bersamaan. ${ }^{33}$ Niebuhr memberikan julukan pada sikap ini sebagai dualis karena terdapat paradoks antara kebenaran Allah dan kebenaran manusia. Manusia ada dalam dosa, keberdosaan manusia tersebut masuk ke dalam pekerjaan manusia namun di sisi lain terdapat anugerah pengampunan Allah terhadap dosa manusia. ${ }^{34}$

Kristus Pengubah Kebudayaan adalah sikap memandang karya Yesus tidak hanya dilihat sebagai aspek yang berada di luar manusia tetapi Kristus juga berkarya dengan sesuatu yang mendalam dan fundamental dalam hidup manusia. ${ }^{35}$ Karena

${ }^{31}$ H. Richard Niebuhr, Christ and Culture, 117.

${ }^{32}$ H. Richard Niebuhr, Christ and Culture, 117.

${ }^{33}$ H. Richard Niebuhr, Christ and Culture, 149.

${ }^{34}$ H. Richard Niebuhr, Christ and Culture, 
telah dibaharui oleh Kristus maka sikap ini menuntut Gereja atau keKristenan untuk membawa pekerjaan budaya dalam kesetiaannya kepada Tuhan yang telah mengubah dan membawa arah baru kepada hidup manusia. ${ }^{36}$

\section{METODE PENELITIAN}

Penelitian ini menggunakan metode kualitatif dengan menggunakan dengan jenis penelitian deskriptif. Metode kualitatif adalah metode penelitian yang digunakan untuk meneliti pada kondisi obyek yang alamiah (sebagai lawannya adalah eksperimen) di mana peneliti adalah instrumen kunci ${ }^{37}$. Penelitian deskriptif bertujuan untuk mendeskripsikan sebab kejadian atau situasi sebagaimana adanya. ${ }^{38}$ Adapun teknik pengumpulan data dilakukan dengan wawancara dengan mendatangi langsung lokasi penelitian. Wawancara dilakukan terhadap beberapa umat Katolik di lokasi penelitian yang terseleksi berdasarkan diskusi dengan dan masukan dari pimpinan Gereja Katolik Paroki Hati Kudus. Teknik wawancara dilakukan dengan metode random purposive yaitu teknik pengambilan data dengan tidak berdasarkan random, strata, atau daerah melainkan berdasarkan atas pertimbangan yang berfokus pada tujuan tertentu.

Penelitian ini menggunakan studi kasus Gereja Katolik Paroki Hati Kudus Tuhan Yesus Ganjuran yang berada di bawah naungan keuskupan agung Semarang. Gereja yang umum dikenal dengan sebutan Gereja Ganjuran ini terletak di dusun Ganjuran, desa Sumbermulyo, kecamatan Bambang lipuro, Bantul. Gereja ini dikenal oleh umat Katolik, peziarah, dan

\footnotetext{
${ }^{36}$ H. Richard Niebuhr, Christ and Culture, 191.

${ }^{37}$ Sugiyono, Memahami Penelitian Kualitatif, (Bandung: CV. Alfabeta, 2012), 1.

${ }^{38}$ Deddy Mulyana, "Metodologi Penelitian Kualitatif “, (Bandung: PT. Remaja Rosdakarya, 2001), 181.
}

masyarakat umum sebagai tempat ibadah dan ziarah yang memiliki nuansa Jawa. Nuansa Jawa itu terlihat dari bentuk arsitektur gereja yang mengambil konsep pendopo yang ada di keraton Yogyakarta, selain itu terdapat juga ornament-ornamen, relief-relief yang menggabungkan unsurunsur keKristenan dengan nuansa Jawa. Salah satu daya tarik di gereja ini adalah keberadaan candi yang bernuansa HinduJawa. Di dalam candi tersebut juga terdapat patung Yesus Kristus dengan penggambaran sebagai seorang Prabu (raja Jawa). Selain itu musik yang digunakan juga menggunakan alat musik Jawa. Nuansa Jawa yang ada di gereja ini merupakan salah satu bentuk proses inkulturasi. Inkulturasi di gereja ini tidak terlepas dari konteks historis yang mendahuluinya. Setiap harinya peziarah maupun pengunjung datang ke tempat ini untuk melakukan ziarah atau untuk merasakan suatu pengalaman yang berbeda dengan gereja-gereja pada umumnya,

Sejarah awal dari paroki hati kudus Tuhan Yesus Ganjuran tidak terlepas dari keberadaan pabrik gula dan perkebunan tebu di Ganjuran. Pemilik dari pabrik gula ini awalnya adalah keluarga Barends dari Belanda yang datang pada tahun 1860 . Sepeninggal bapak Stefanus Barends pada tahun 1887, usaha dilanjutkan oleh Ferdinand Barends dan istri dari S. Barends, Ibu Wilhemina Kartaus menikah lagi dengan Gottfried Schmutzer. Sepeninggal, ibu Wilhemina Kartaus pada tahun 1912, usaha pabrik gula S. Barends dibeli dari dua anak dari perkawinan ibu Wilhemina Kartaus dan Gottfried Schmutzer. ${ }^{39}$

Dalam menjalankan bisnis usaha perkebunan tebu dan pabrik gula di Ganjuran, Schumutzer juga berkarya di bidang sosial, dan pengembangan iman.

39 Panitia 90 tahun Ganjuran, "Terpanggil Mengemban Berkat" (Ganjuran, Bantul; Gereja Hati Kudus Tuhan Yesus Ganjuran, 2014), 28-29. 
Karya Schmutzer dalam bidang sosial dilakukan dengan membangun rumah sakit bagi masyarakat sekitar serta mendirikan sekolah dasar untuk anak laki-laki dari desa dan asrama untuk anak perempuan. ${ }^{40}$ Dalam bidang pengembangan iman, Schmutzer mendirikan gereja kecil untuk karyawan dan masyarakat.,

Seiring berjalannya waktu gereja kecil yang dibangun Schmutzer tidak mampu lagi menampung umat karena bertambahnya umat oleh karena itu Schmutzer mengusahakan pendirian gedung permanen ${ }^{41}$ Dalam membangun gedung gereja, Schmutzer berkeinginan untuk membangun gedung gereja dengan corak nuansa Jawa. Schmutzer ingin untuk menghidupi imannya dalam konteks di mana mereka tinggal. Dasar inilah yang menjadi dasar pertama dari inkulturasi di Gereja Ganjuran. Untuk melaksanakan niat tersebut, Schmutzer meminta restu dari Takhta Suci untuk membangun gereja dengan corak Jawa. ${ }^{42}$ Namun pada saat itu hanya patung altar Jawa dan patung Hati Kudus yang disetujui oleh Takhta Suci sedangkan bentuk bangunan masih menggunakan gaya bangunan Belanda. Pembangunan diselesaikan pada tahun 1924 dan altar diberkati pada tahun yang sama dengan dihadiri Vicaris Apostolik Batavia, Mgr A. Van Velsen SJ. ${ }^{43}$

Pada tahun 1927, Schmutzer membangun sebuah candi. Candi tersebut didirikan sebagai monument ungkapan syukur Schmutzer yang lolos dari krisis keuangan yang melanda dunia. Maksud luhur dari pembangunan candi itu oleh

40 Panitia 90 tahun Ganjuran, "Terpanggil Mengemban Berkat", 34-35.

41 Panitia 90 tahun Ganjuran, "Terpanggil Mengemban Berkat", 39.

${ }^{42}$ Gereja Hati Kudus Tuhan Yesus Ganjuran, "Sejarah Gereja Ganjuran", last modified 18 Juni 2019, diakses 31 Juli 2019, http://www.gerejaganjuran.org/gereja-ganjuran.

${ }^{43}$ Panitia 90 tahun Ganjuran. "Terpanggil Mengemban Berkat", 39-40. keluarga Schmutzer untuk mengingatkan peranan Kristus Raja di kalangan perkebunan tebu di Ganjuran ${ }^{44}$ Candi itu juga mempunyai maksud untuk menyerahkan pulau Jawa kepada Hati Kudus Tuhan Yesus. ${ }^{45}$

Pada tahun 2006, gempa bumi melanda Yogyakarta dan meluluhlantahkan Yogykarta. Efek dari gempa tersebut juga dirasakan oleh umat paroki Hati Kudus Tuhan Yesus Ganjuran. Gedung gereja lama yang dibangun Schmutzer runtuh namun candi hati kudus Tuhan Yesus tidak rusak akibat gempa. Walaupun begitu umat tidak patah semangat, pada agustus $2006 \mathrm{di}$ bangun gereja darurat beratapkan daun kelapa di depan candi. ${ }^{46}$ Pembangunan kembali gedung gereja dilakukan pada tahun 2008 dan selesai pembangunan pada 31 Juli 2009 diberkati pada minggu 23 agustus 2009. ${ }^{47}$ Bentuk bangunan gereja yang baru berbentuk joglo pengrawit yang terbuka melambangkan keterbukaan Allah kepada umatNya dan menjadi sebuah ajakan agar Gereja membuka diri bagi siapa saja. $^{48}$

\section{HASIL DAN PEMBAHASAN}

Dalam melakukan penelitian, penulis mengambil sampel beberapa umat yang berada di lokasi melakukan penelitian atau yang tinggal di sekitarnya. Dari hasil wawancara terhadap beberapa informan,

${ }^{44}$ Gereja Hati Kudus Tuhan Yesus Ganjuran, "Sejarah Candi Ganjuran", last modified 18 Juni 2019, diakses pada 31 Juli 2019, http://www.gerejaganjuran.org/candi-ganjuran.

${ }^{45}$ Gereja Hati Kudus Tuhan Yesus Ganjuran, "Sejarah Candi Ganjuran", last modified 18 Juni 2019, diakses pada 31 Juli 2019, http://www.gerejaganjuran.org/candi-ganjuran.

46 Panitia 90 tahun Ganjuran, Terpanggil Mengemban Berkat, 74.

47 Panitia 90 tahun Ganjuran, Terpanggil Mengemban Berkat, 75-77.

${ }_{48}$ Panitia 90 tahun Ganjuran, Terpanggil Mengemban Berkat, 78. 
penulis menemukan ada beberapa pandangan, tanggapan dari umat Gereja Ganjuran mengenai inkulturasi serta dampaknya terhadap kehidupan mereka seperti terangkum di bawah ini.

\section{Pandangan Umat terhadap Inkulturisasi}

Responden pertama, memandang inkulturasi sebagai bentuk penyesuaian dan pemasukan pesan-pesan injil ke dalam suatu budaya supaya pesan Injil dan iman Kristen dapat mudah untuk dipahami dan dihayati. Responden menambahkan bahwa usaha inkulturasi itu diprakarsai oleh keluarga Schmutzer dari Belanda yang mempunyai pabrik gula (wilayah sekitar gereja) yang secara aktif berkarya bagi kepentingan masyarakat sekitar dan juga concern terhadap pengembangan injil di masyarakat Ganjuran. ${ }^{49}$

Responden kedua, memandang inkulturasi sebagai upaya pengakaran Injil ke dalam budaya setempat (budaya Jawa). Inkulturasi di Gereja Ganjuran diprakarsai oleh Schmutzer yang cinta dengan budaya Jawa yang berusaha untuk bagaimana menghayati iman dengan berakar pada budaya setempat. $^{50}$

Responden ketiga, memandang inkulturasi sebagai upaya untuk menyesuaikan diri dengan budaya setempat (budaya Jawa). ${ }^{51}$ Responden keempat memandang inkulturasi sebagai upaya untuk memahami pewartaan Injil atau iman keKristenan dengan melihat unsur-unsur budaya setempat supaya pewartaan Injil dan iman Kristen yang dilakukan gereja bukan sesuatu yang asing dengan budaya setempat

49 Responden D, wawancara, (Yogyakarta, Ganjuran: 26 Juli 2019).

50 Responden T. wawancara, (Yogyakarta, Ganjuran: 26 Juli 2019).

51 Responden K, wawancara, (Yogyakarta, Ganjuran: 26 Juli 2019). sehingga membantu untuk menghayati pesan pewartaan iman. ${ }^{52}$

Responden kelima memandang inkulturasi sebagai pemasukan budaya Jawa dalam liturgi misa. ${ }^{53}$ Responden keenam memandang inkulturasi sebagai cara penghayatan ibadah dengan memeasukkan unsur budaya Jawa. ${ }^{54}$

Responden ketujuh memandang inkulturasi sebagai cara untuk meresapi iman dengan memakai budaya setempat (budaya Jawa) sehingga penghayatan iman semakin mantap. ${ }^{55}$ Responden kedelapan memandang inkulturasi sebagai pengangkatan budaya setempat dan diangkat ke dalam liturgi atau misa perayaan Ekaristi. Responden juga menyatakan bahwa inkulturasi tidak ada dalam kamus-kamus pada umumnya dan hanya ada dalam kamus Gereja. ${ }^{56}$

\section{Tanggapan Umat terhadap Inkulturasi di Paroki Hati Kudus Tuhan Yesus Ganjuran}

Penelitian yang dilakukan oleh penulis juga bermaksud untuk mengetahui tanggapan responden terhadap inkulturasi di Paroki Hati Kudus Tuhan Yesus Ganjuran. Penulis kemudian menentukan dua pertanyaan untuk mengetahui tanggapan atau respon dari responden, yaitu:

i) Apa tanggapan umat terhadap inkulturasi di Paroki Hati Kudus Tuhan Yesus Ganjuran?

ii) Apakah inkulturasi di Paroki Hati Kudus Tuhan Yesus Ganjuran bertentangan dengan pesan Injil dan iman Kristen?

52 Responden A, wawancara, (Yogyakarta, Ganjuran: 26 Juli 2019).

53 Responden Ro, wawancara, (Yogykarta, Ganjuran: 26 Juli 2019).

54 Responden Ri, wawancara, (Yogykarta, Ganjuran: 26 Juli 2019).

55 Responden B, wawancara, (Yogykarta, Ganjuran: 27 Juli 2019).

56 Responden Bu, wawancara, (Yogakarta, Ganjuran: 27 Juli 2019). 
Dari pertanyaan yang pertama, penulis menemukan bahwa tanggapan responden terhadap inkulturasi di Paroki Hati Kudus Tuhan Yesus Ganjuran adalah positif. Ada tiga alasan yang diberikan oleh responden, yaitu (i) inkulturasi membantu responden untuk menghayati imannya di tengah budaya mereka yang masih melekat sehingga penghayatan iman mereka dapat dihayati. ${ }^{57}$ (ii) responden melihat bahwa dengan inkulturasi mereka dapat merasakan bahwa Kristus itu dekat dengan umat. ${ }^{58}$ (iii) karena inkulturasi membuat umat semakin menghayati makna misa Ekaristi. ${ }^{59}$

Dari pertanyaan kedua, penulis menemukan lima tanggapan umat terkait apakah inkulturasi bertentangan dengan pesan Injil dan iman Kristen. Tanggapan pertama, inkulturasi di Gereja Ganjuran tidak bertentangan dengan iman Kristen selama inkulturasi yang ada di Gereja Ganjuran tidak merusak pesan inti dari pewartaan injil dan iman Kristen. ${ }^{60}$

Tanggapan kedua, inkulturasi yang ada di Gereja Ganjuran tidak bertentangan dengan iman Kristen selama inkulturasi yang dilakukan tidak membawa umat kepada praktik-praktik atau ritual-ritual negatif yang mengarah kepada penyembahan berhala atau semacamnya. ${ }^{61}$

Tanggapan ketiga, inkulturasi di Gereja Ganjuran tidak bertentangan dengan iman Kristen dan membawa umat kepada penghayatan yang mendalam terhadap misteri iman.

Tanggapan keempat, inkulturasi di Gereja Ganjuran tidak bertentangan dengan

57 Hasil Wawancara dengan responden, (Yogyakarta, Ganjuran: 26 s/d 27 Juli 2019).

58 Hasil wawancara dengan responden, (Yogyakarta, Ganjuran: 26 s/d 27 Juli 2019).

59 Hasil wawancara dnegan responden, (Yogyakarta, Ganjuran: 26 s/d 27 Juli 2019).

60 Hasil wawancara dengan responden, (Yogyakarta, Ganjuran: 26 s/d 27 Juli 2019).

61 Hasil wawancara dengan responden, (Yogyakarta, Ganjuran: 26 s/d 27 Juli 2019). iman Kristen selama inkulturasi tersebut tidak menyimpang dari hakikat liturgi. ${ }^{62}$

Tanggapan kelima, inkulturasi di Gereja Ganjuran tidak bertentangan dengan pesan Injil dan iman Kristen karena setiap agama melekat dengan simbol-simbol yang dipakai untuk membuat umat mampu menghayati nilai dan makna suatu pesan. ${ }^{63}$

\section{Dampak Inkulturasi bagi Kehidupan Peribadahan Umat}

Dari penelitian terhadap para responden, penulis menemukan bahwa inkulturasi di gereja ini memiliki dampak dan pengaruh bagi kehidupan umat. Responden pertama merasakan dampak atau pengaruh inkulturasi di Gereja Ganjuran pada semangat untuk terus berdoa dan berdevosi. Responden melihat bahwa umat yang berdoa dan berdevosi di Gereja Ganjuran benar-benar khusyuk dalam berdoa dan berdevosi. Responden juga merasakan suatu pengalaman yang berbeda ketika berdoa dan berdevosi di Gereja Ganjuran dibandingkan dengan tempat lain. $^{64}$

Responden kedua merasakan pengaruh inkulturasi di Gereja Ganjuran pada ibadahnya. Responden melihat bahwa walaupun misa berlangsung cukup lama tetapi umat dapat begitu khusyuk dalam menghayati misa perayaan ekaristi. ${ }^{65}$

Responden ketiga merasakan dampak atau pengaruh inkulturasi di Gereja Ganjuran dalam semangat untuk berdoa. Responden merasakan ada perasaan damai dan tentram ketika berdoa dan membuatnya terdorong untuk terus datang dan berdoa kepada Hati Kudus Yesus. Responden juga

62 Hasil wawancara dengan responden, (Yogyakarta, Ganjuran: 26 s/d 27 Juli 2019).

63 Hasil wawancara dengan responden, (Yogyakarta, Ganjuran: 26 s/d 27 Juli 2019).

${ }^{64}$ Responden D, Wawancara, (Yogyakarta, Ganjuran: 26 Juli 2019).

${ }^{65}$ Responden T, Wawancara, (Yogyakarta, Ganjuran: 26 Juli 2019). 
memberikan pengalaman bahwa banyak doanya yang terkabulkan dan juga masalah dalam kehidupannya dapat diselesaikan. ${ }^{66}$ Responden keempat merasakan dampak atau pengaruh inkulturasi di Gereja Ganjuran di mana penghayatan iman dan pesan-pesan injil mudah untuk dipahami dan dirasakan. ${ }^{67}$

Menurut responden kelima, inkulturasi di Gereja Ganjuran memberikan ketenangan ketika menghayati makna ibadah, berdoa, atau berdevosi, ${ }^{68}$ bahkan responden memberikan pengalaman ada banyak permohonan yang dikabulkan. Responden keenam memiliki kesamaan dengan responden kelima, di mana merasakan ketenangan batin ketika berdoa dan berdevosi, dan mendorongnya untuk semakin belajar untuk menghayati pesan injil dan iman keKristenan. ${ }^{69}$

Responden ketujuh merasakan dampak atau pengaruh inkulturasi dalam menghayati misa dan perayaan ekaristi di mana responden dapat merasakan kedamaian dan ketenangan terutama ketika beribadah dan berdoa. ${ }^{70}$ Sedangkan responden kedelapan tidak memberikan apa dampak dan pengaruh inkulturasi bagi kehidupan umat.

\section{Analisis Dan Pembahasan}

Berdasarkan pada hasil temuan yang diperoleh di lapangan, penulis menemukan bahwa umat paroki Hati Kudus Yesus Ganjuran memiliki pemahaman atau pandangan terhadap inkulturasi. Umat memandang bahwa inkulturasi merupakan suatu upaya untuk menyesuaikan dan

${ }^{66}$ Responden K, Wawancara, (Yogyakarta, Ganjuran: 26 Juli 2019).

${ }^{67}$ Responden A, Wawancara, (Yogyakarta: Ganjuran: 26 Juli 2019).

${ }^{68}$ Responden Ro, Wawancara, (Yogyakarta, Ganjuran: 26 Juli 2019).

${ }^{69}$ Responden Ri, Wawancara, (Yogyakarta, Ganjuran: 26 Juli 2019).

${ }^{70}$ Responden B, Wawancara, (Yogyakarta, Ganjuran: 26 Juli 2019). mengakarkan pesan-pesan Injil ke dalam suatu budaya setempat sehingga pewartaan Injil bisa diterima dan dihayati secara mendalam dan menumbuhkan pengalaman iman umat. Pandangan umat terhadap inkulturasi ini sesuai dengan definisi A.B Sinaga dan A. Soenarja. A.B Sinaga dan A. B Sinaga memandang dan memberikan definisi inkulturasi sebagai penyesuaian dan adaptasi kepada suatu masyarakat tertentu sehingga Injil yang diwartakan dapat dimengerti dan dipahami. ${ }^{71}$ A. Soenarja juga memberikan definisi yang sama seperti A.B Sinaga bahwa inkulturasi adalah usaha untuk masuk ke dalam suatu kultur, dan menjadi senyawa dengan suatu kultur. ${ }^{72}$ Usaha inkulturasi digiatkan dalam Gereja Katolik sehingga pesan Injil yang diwartakan gereja dapat membawa umat untuk menghayati pesan Injil dan menghidupinya.

Dari pandangan umat terhadap Inkulturasi, penulis menemukan fakta bahwa inkulturasi menurut pandangan umat Gereja Ganjuran. ${ }^{73}$ didasarkan pada analogi misteri inkarnasi Allah yaitu penjelmaan Sabda Allah ke dalam dunia. Hal ini karena umat memandang dan memahami inkulturasi sebagai sebagai upaya untuk menyesuaikan dan mengakarkan Injil ke dalam suatu budaya. Peristiwa Inkarnasi dipahami sebagai Allah yang datang, menjelma, dan menyapa manusia. Ketika Allah menjelma menjadi manusia, Ia menghidupi hidup manusia, Ia berbicara dalam bahasa manusia, Ia hidup dalam budaya manusia dan menggunakan budaya sebagai cara Allah mewartakan keselamatan Allah. ${ }^{74}$ Dalam teologi Konsili Vatikan II

${ }_{71}^{71}$ A.B Sinaga, "Gereja dan Inkulturasi", 8.

A. Soenarja, "Inkulturisasi

(Indonesianisasi): Kepemimpinan dan Kekeluargaan dalam Biara di Indonesia di masa sekarang “, 5.

73 Untuk selanjutnya penulis akan menggunakan istilah Gereja Ganjuran

74 Yunita Setyoningrum, "TINJAUAN INKULTURASI AGAMA KATOLIK DENGAN 
penggunaan inkulturasi digunakan sebagai dasar awal dalam inkulturasi. Implikasi dari penggunaan analogi inkarnasi dalam upaya inkulturasi bagi Gereja adalah Gereja harus "berinkarnasi" dengan budaya di mana Ia dipanggil dan diutus dan menjadi senyawa dengan kultur sehingga pewartaan keselamatan yang diwartakan gereja dapat menjadi bermakna dan hidup. ${ }^{75}$ Beberapa umat juga menjelaskan hal yang sama, mereka memandang bahwa upaya inkulturasi dilakukan untuk menyesuaikan dengan kebudayaan setempat.

Terkait tanggapan umat terhadap inkulturasi di Gereja Ganjuran dan tanggapan mereka terhadap apakah inkulturasi yang dilakukan di Gereja Ganjuran bertentangan dengan iman kekistenan, penulis menemukan bahwa respon umat terhadap inkulturasi bernilai positif karena dengan upaya inkulturasi membantu umat menghayati pesan Injil dan membantu mereka untuk menghayati ibadah. Terkait apakah inkulturasi di Gereja Ganjuran bertentangan dengan iman Kristen, penulis menemukan dua respon utama. Pertama, umat memandang bahwa inkulturasi di Gereja Ganjuran tidak bertentangan dengan iman Kristen dan memandang ketika umat menggunakan budaya mereka (budaya Jawa) umat semakin di bawa untuk menghidupi panggilan iman mereka. Umat juga memandang bahwa dengan menggambarkan Kristus dengan

BUDAYA JAWA PADA BANGUNAN GEREJA KATOLIK DI MASA KOLONIAL BELANDA (STUDI KASUS: GEREJA HATI KUDUS YESUS, PUGERAN, YOGYAKARTA): ANALYSIS OF CHRISTIAN INCULTURATION TO JAVANESE CULTURE ON CATHOLIC CHURCH BUILT ON THE DUTCH COLONIAL PERIOD (STUDI KASUS : THE CHURCH OF SACRED HEART, PUGERAN, YOGYAKARTA)", Jurnal Ambiance 1, no. $1,5$.

A. Soenarja, Inkulturisasi (Indonesianisasi): Kepemimpinan dan Kekeluargaan dalam Biara di Indonesia di masa sekarang, 6. penggambaran budaya Jawa merasakan bahwa Kristus itu yang hadir dan dekat dengan umat yang masih lekat dengan budaya Jawa mereka. Kedua, umat memandang inkulturasi di Gereja Ganjuran tidak saling bertentangan akan tetapi walaupun umat menanggapi bahwa inkulturasi tersebut tidak bertentangan dengan iman Kristen namun mereka berpendapat bahwa jangan sampai inkulturasi yang dilakukan di Gereja Ganjuran membawa umat kepada praktikpraktik negatif atau berhala yang akan merusak maksud dari inkulturasi itu sendiri dan juga menggeser nilai-nilai iman Kristen. Bila ditinjau dari teori hubungan Kristus dengan kebudayaan yang dijelaskan oleh R. Niebuhr, penulis berkesimpulan bahwa dari dua sikap atau respon utama umat Gereja Ganjuran terhadap inkulturasi dan hubungan antara iman dengan kebudayaan adalah Kristus dari kebudayaan dan Kristus dan kebudayaan dalam paradoks. Sikap pertama adalah Kristus dari kebudayaan. Menurut Niebuhr, Gereja yang mengambil sikap ini mengakomodasikan Kristus dan kebudayaan. ${ }^{76}$ Pada sikap Gereja ini, Kristus dipahami melalui kebudayaan. Umat di Gereja Ganjuran yang melekat dengan kebudayaan Jawanya dapat meresapi dan menghayati pesan Injil melalui budaya mereka dan dengan begitu mereka dapat menghidupi iman mereka melalui kebudayaan mereka. Sikap utama kedua dari umat Gereja Ganjuran terhadap inkulturasi di Gereja Ganjuran dan tanggapan mereka terhadap apakah inkulturasi itu bertentangan dengan iman Kristen, adalah Kristus dan budaya dalam paradoks. Pada sikap ini, Gereja berkeinginan untuk mempertahankan kesetiaan mereka kepada Kristus tetapi di sisi lain ingin mempertahankan tanggung Jawab mereka terhadap budaya mereka

\footnotetext{
${ }^{76}$ H. Richard Niebuhr, "Christ and Culture",
} (New Yorks: Harper Torchbooks, 1975), 83-84. 
secara bersamaan. ${ }^{77}$ Niebuhr melihat adanya suatu paradoks. Tanggapan umat terhadap inkulturasi memang bermakna positif karena dengan dapat memahami dan menghayati pesan Injil dengan menggunakan budaya mereka (budaya Jawa). Namun di sisi lain mereka juga melihat adanya suatu implikasi lain dari inkulturasi di Gereja Ganjuran yang bisa bernilai negatif yang akan membawa umat kepada suatu pemaknaan atau praktikpraktik yang menyimpang dari tujuan inkulturasi dan inti iman Kristen itu sendiri.

Terkait dampak atau pengaruh inkulturasi bagi kehidupan umat, penulis menemukan bahwa umat memberikan pengalaman akan dampak atau pengaruh inkulturasi bagi kehidupan mereka namun kebanyakan umat/responden merasakan dampak atau pengaruh inkulturasi tersebut dalam dua hal. Pertama, dalam liturgi dan menghayati makna misa perayaan ekaristi. Ketika umat merayakan misa, banyak umat yang secara khusyuk mendalami perayaan ekaristi walaupun misa berlangsung hingga memakan waktu yang lama. Untuk masuk mengapa kebanyakan umat merasakan dampak inkulturasi pertama dalam liturgi misa Ekaristi perlu ditinjau terlebih dahulu hakikat liturgi. Penulis mengambil pandangan dari Konsili Vatikan II. Menurut konsili Vatikan II, Kristus selalu mendampingi GerejaNya terutama dalam kegiatan-kegiatan liturgis, Ia hadir dalam rupa Ekaristi selain itu adalah puncak dan sumber kehidupan Gereja karena "liturgi terutama dari Ekaristi, bagaikan dari sumber, mengalirlah rahmat kepada kita dan dengan hasil guna yang amat besar diperoleh pengudusan manusia dan pemuliaan Allah dalam Kristus, tujuan semua karya Gereja lainnya." ${ }^{78}$ Menurut 149.

${ }^{77}$ H. Richard Niebuhr, "Christ and Culture",

78 Konsili Vatikan II, diterjemahkan, "Dokumen Konsili Vatikan II", (Jakarta: Penerbit OBOR, 2013), 5-7. penulis, alasan mengapa kebanyakan umat merasakan dampak atau pengaruh dari Inkulturasi dari misa Ekaristi karena dalam perayaan Ekaristi, umat diajak untuk menghayati kehadiran Kristus dalam ekaristi. Ekaristi berarti Kristus hadir, serta tinggal di tengah umat-Nya. ${ }^{79}$ Ketika umat masuk kekhusyukan ke dalam kekhusyukan misa Ekaristi, umat dibawa untuk menghayati kehadiran Kristus di tengahtengah umatNya. Inkulturasi membuat umat yang masih melekat dengan budaya Jawa dapat merasakan makna Ekaristi dengan khidmat dan penghayatan penuh. Dampak kedua dari inkulturasi di Gereja Ganjuran terlihat dari semangat untuk terus berdoa dan berdevosi kepada Hati Kudus Yesus. Umat merasakan adanya rasa damai dan tentram ketika berdoa dan berdevosi kepada Hati Kudus Yesus. Inkulturasi itu mampu mendorong umat untuk terus mengobarkan semangatnya untuk berdoa dan berdevosi sehingga banyak umat yang penulis tanyakan memberikan pengalaman di mana banyak doanya yang terkabulkan. Dari tanggapan umat, penulis menyimpulkan bahwa inkulturasi di Gereja Ganjuran memberikan dampak atau pengaruh dalam kehidupan umat. Hal itu sesuai dengan tujuan dari inkulturasi itu sendiri yaitu untuk membawa umat untuk menghayati iman mereka dengan budaya mereka. Penulis juga menyimpulkan bahwa inkulturasi tidak hanya membawa umat untuk menghayati pesan injil dengan budaya mereka tetapi juga mendorong spiritual mereka untuk menghidupi pengalaman iman mereka dalam berdoa dan berdevosi.

Dari penelitian yang penulis lakukan, penulis melihat bahwa dengan inkulturasi di Gereja Ganjuran, membuat umat makin mampu untuk menghayati pesan Injil dan

79 Emanuel Martasudjita, Ekaristi: Makna dan Kedalamannya bagi Perutusan di tengah Dunia, (Yogyakarta: Penerbit Kanisius, 2012), 40. 
iman. Tetapi menurut penulis ada tantangan yang harus dihadapi Paroki Hati Kudus Tuhan Yesus Ganjuran terkait dengan inkulturasi di gereja ini yaitu tantangan zaman yang akan terus berganti, dan generasi yang akan terus berganti, sehingga pemaknaan pun akan berganti. Apakah di kemudian hari umat di masa depan dapat memaknai inkulturasi di gereja ini atau tidak? ${ }^{80}$ Ini merupakan tantangan yang harus dihadapi Paroki Hati Kudus Tuhan Yesus Ganjuran. Bagaimana Gereja Ganjuran akan tetap menanamkan nilai dan makna inkulturasi di gereja ini di masa yang akan mendatang. Selain itu perlu dicermati oleh pemimpin Gereja Paroki Hati Kudus Tuhan Yesus Ganjuran mengenai bahaya sinkretisme yang mungkin terjadi tanpa atau dengan sepengetahuan dari para pemimpin gereja. Penulis, yang bukan umat di Paroki Hati Kudus Tuhan Yesus Ganjuran, hanya bisa menyarankan agar pihak gereja secara rutin memberikan pengarahan kepada umat perlu dilakukan agar paham dan gaya hidup mereka sebagai orang Kristen tidak tercampuradukan dengan kepercayaan ataupun agama lain. Juga memberikan pengertian bagi umat di masa depan tentang sejarah dan makna inkulturasi di gereja ini sehingga inkulturasi di gereja ini tidak hanya menyentuh kulit luarnya saja tetapi juga benar-benar dimaknai dalam kehidupan beriman.

\section{KESIMPULAN DAN SARAN}

Dari hasil penelitian penulis menyimpulkan bahwa umat Paroki Hati

${ }^{80}$ Tantangan itu juga disebutkan oleh Peter Schniller "...The older, more established churches in turn must renounce any superiority complex and must encourage and support the younger churches in their search for authentic inculturation. The shape of these new churches may be quite different and surprising...", dalam Peter Schineller, "Inculturation: a difficult and delicate task," International Bulletin of Mission Research 20, (July 1996): 110.
Kudus Tuhan Yesus Ganjuran memandang inkulturasi sebagai usaha untuk menyesuaikan dan mengakarkan pesan Injil ke dalam suatu budaya setempat yang mana dalam penelitian ini adalah budaya Jawa. Pandangan umat ini menggunakan analogi Inkarnasi Sabda Allah ke dalam daging, yang menjelma menjadi manusia. Umat di Paroki Hati Kudus Yesus Ganjuran memandang inkulturasi di Paroki Hati Kudus Tuhan Yesus Ganjuran memiliki nilai positif dan tidak bertentangan dengan iman Kristen, karena membuat mereka mudah untuk memahami, meresapi, dan menghayati pesan-pesan Injil dalam kehidupan mereka selama tidak menyimpang dari tujuan dari inkulturasi dan pewartaan Injil. Umat juga merasakan dampak atau pengaruh inkulturasi dalam kehidupan mereka di mana mereka mampu untuk menghayati makna Ekaristi dan mendorong mereka untuk terus semangat untuk berdoa dan berdevosi.

\section{DAFTAR PUSTAKA}

Angelico, Jose Pedro. Inculturation as SelfIdentification: An African Research in Search of Authentic Christian Identity: A Theological Enquiry Amon The Ewe of Ghana. Disertasi. Universidade Catolica Portoguesa, 2016.

Bakker, J.W.M. Filsafat Kebudayaan:Sebuah Pengantar. Yogyakarta: Penerbit Kanisius, 1984.

Boli Ujan SVD, Penyesuaian dan Inkulturasi Liturgi, http://www.katolisitas.org/penyesuaia n-dan-inkulturasi-liturgi/Elihami, Lucia Esti. Sejarah Berdirinya Paroki Hati Kudus Yesus Ganjuran: Inkulturasi Sebagai Landasan Tumbuh dan Berkembangnya Paroki Hati Kudus Yesus Ganjuran. Skripsi. Universitas Sanata Dharma: Yogyakarta, 1995. 
Dixon, R.L, Injil dan kontekstualisasi: Sebuah cara kontekstualisasi masa kini yang kurang memadai, Jurnal Pelita Zaman, 11(2), 1996

Gereja Hati Kudus Tuhan Yesus Ganjuran, Sejarah Gereja Ganjuran, diakses 31 Juli 2019,

http://www.gerejaganjuran.org/gereja -ganjuran.

Gereja Hati Kudus Tuhan Yesus Ganjuran, Sejarah Candi Ganjuran, diakses 31 Juli 2019,

http://www.gerejaganjuran.org/candiganjuran

Herusatoto, Budiono. Simbolisme Jawa. Yogyakarta: Penerbit Ombak, 2008.

Konsili Vatikan II. Diterjemahkan. Dokumen Konsili Vatikan II. Cetakan kesebelas. Jakarta:Penerbit Obor, 2012.

Martasudjita, Emanuel. Ekaristi: Makna dan Kedalamannya bagi Perutusan di tengah Dunia. Yogyakarta: Penerbit Kanisius, 2012.

Mulyana, Deddy. Metodologi Penelitian Kualitatif. Bandung: PT. Remaja Rosdakarya, 2001.

Niebuhr, H. Richard. Christ and Culture. New York: Harper Tochbooks, 1975.

Panitia 90 tahun Ganjuran. Terpanggil Mengemban Berkat. Bantul, Yogykarta: Gereja Hati Kudus Tuhan Yesus Ganjuran, 2014.

Paulus II, Yohanes. Gereja di Asia (Church in Asia): Anjuran Apostolik Pasca Sinodal, New Delhi, 6/11/1999. Cetakan keempat. Jakarta: Departemen Dokumentasi dan Penerangan, Konferensi WaliGereja Indonesia, 2010.

Prastowo, Yohanes Agung Hari. Peranan Inkulturasi Budaya Jawa terhadap Penghayatan Ekaristi di Paroki Hati Kudus Tuhan Yesus Ganjuran. Skripsi. Universitas Sanata Dharma, 2012.
Prom, Rodney L. The Inculturation of the Gospel: Implication for the Methodist Church the Gambia's Quest for Church Leadership. Tesis., University of Manchester, 2013.

Schineller, Peter.1996. "Inculturation: A Difficult and Delicate Task." International Bulletin of Mission Research 20: (July 1996): 109-112.

Shorter, Aylward. Toward A Theology of Inculturation. New York: Orbis Books, 1988

Setyoningrum, Yunita. 2009. "TINJAUAN INKULTURASI AGAMA KATOLIK DENGAN BUDAYA JAWA PADA BANGUNAN GEREJA KATOLIK DI MASA KOLONIAL BELANDA (STUDI KASUS : GEREJA HATI KUDUS YESUS, $\quad$ PUGERAN, YOGYAKARTA): ANALYSIS OF CHRISTIAN INCULTURATION TO JAVANESE CULTURE ON CATHOLIC CHURCH BUILT ON THE DUTCH COLONIAL PERIOD (STUDI KASUS : THE CHURCH OF SACRED HEART, PUGERAN, YOGYAKARTA", Jurnal Ambiance 1, no. 2 (2009): 1-23

Sinaga, Ancetus B. Gereja dan Inkulturasi. Yogyakarta: Penerbit Kanisius, 1984

Soenarja, A. Inkulturasi (Indonesianisasi): Kepemimpinan dan Kekeluargaan dalam Biara Indonesia di Masa Sekarang. Yogyakarta: Pemerbit Kanisius, 1977.

Sugiyono. Memahami Penelitian Kualitatif. Bandung: CV. Alfabeta, 2012.

Suradi. "BENTUK KOMUNIKASI

DALAM MENJALANKAN PROSES ENKULTURASI BUDAYA (Studi Pada Masyarakat Suku Dayak Kenyah di Desa Pampang, Kecamatan Samarinda Utara)". eJournal Ilmu Komunikasi 4, no. 1 (2016):160-173, diakses April 
Jurnal Gamaliel : Teologi Praktika

Vol 2, No 1, Maret 2020

11, 2019. https://ejournal.ilkom.fisipunmul.ac.id/site/?p=2356.

Suseno, Franz Magnis. Katolik itu Apa?: Sosok, Ajaran, dan Kesaksiannya. Yogyakarta: Penerbit Kanisius, 2017. 